\title{
Treatment of female stress urinary incontinence with transobturator suburetral band compared with single incision sling: 7-year follow-up
}

\begin{abstract}
Objetives: Compare the efficacy and post-surgical complications of single-incision sling (SIS) and transobturator band (TO) for the treatment of stress urinary incontinence (SUI) over 7 years' follow up.

Methods: This is a prospective observational study that included 289 women with SUI who went under surgical treatment, either TO (109) or SIS (180). Patients were evaluated pre- and postoperatively through anamnesis, physical examination and ultrasound. Epidemiological information, complications and surgical time were recorded. The primary outcomes were total continence, objective and subjective cure rates at 7-year follow-up.
\end{abstract}

Statistics: T-Student or U-Mann-Whitney for quantitative variables, Chi-Square for qualitative variables.

Results: The groups were similar regarding demographic and medical history parameters, except for age and arterial hypertension, which were higher in TO group, and that SIS patients were more physically active tan TO patients. The TO band compared to SIS associated with increased frequency repair of pelvic organ prolapse. Depending on the type of urinary incontinence, pure SUI was more frequent in SIS and mixed in TO. The duration of the surgery was shorter with SIS. During the 7-year follow up there were no differences in the objective cure, subjective cure and complication rates.

Conclusion: After 7-years follow-up, no significant differences were found with regard to subjective and objective outcomes, and post-surgery complication rates between the single incisión sling and the transobturator band.

Keywords: transobturator band, single incision sling, objective continence, complications, long-term follow-up
Volume 12 Issue I - 202I

Carmen E Badillo-Bercebal,' Sonia DeMiguel-Manso, ',2 Elena García-García,' Dakota Viruega-Cuaresma,' Julio A Gobernado-Tejedor,' María López-País' 'Servicio de Obstetricia y Ginecología, Hospital Clínico Universitario de Valladolid, Gerencia Regional de Salud de Castilla y León (SACYL), España, Spain

2Departamento de Pediatría e Inmunología, Obstetricia y Ginecología, Nutrición y Bromatología, Psiquiatría e Historia de la Ciencia, Facultad de Medicina, Universidad de Valladolid, España, Spain

Corresponding Author: Carmen E Badillo-Bercebal, Servicio de Obstetricia y Ginecología, Hospital Clínico Universitario de Valladolid, Gerencia Regional de Salud de Castilla y León (SACYL), Avenida Ramón y Cajal 3,47005 Valladolid, España, Spain,Tel+346621 I7121, Email carmen.e.badillo@gmail.com

Received: December 12, 2020 | Published: January 21, 202 |
Abbreviations: SUI, stress urinary incontinence; UI, urinary incontinence; TO, transobturator band; SIS, single incisión sling; PVR, postvoid residue; UDS, urodynamic study; MUI, mix urinary incontinence; BMI, age and body mass index; POP, pelvic organ prolapse; DS, standard desviation; Ns, not significant; $\mathrm{AH}$, arterial hypertension; ITU, infección del tracto urinario; RCT, randomized controlled trial

\section{Introduction}

Stress urinary incontinence (SUI) is the most common type of incontinence, representing $50 \%$ of cases. It is defined as the involuntary loss of urine that occurs with physical effort, coughing, sneezing, exercise or any manoeuver that increases intra-abdominal pressure. The overall women prevalence is estimated at between $12 \%$ and $46 \%{ }^{1}$ This high prevalence represents a significant individual and social burden, in economic and quality of life terms. Advanced age, parity, vaginal delivery, obesity, and menopause are factors associated with an increased risk of urinary incontinence (UI).

SUI is usually due to a mechanical or anatomical defect, or weakness of the urethra or pelvic floor; this is why the therapeutic approach tends to focus on mechanical therapies, such as surgery. In clinical practice there are numerous non-surgical therapies such as lifestyle modification, bladder reeducation or rehabilitation of the pelvic floor muscles. When conservative therapies fail, surgery is offered. For these patients, there are numerous corrective surgical techniques: retropubic and transobturator tension-free suburethral bands, single-incision sling or Burch colposuspension. ${ }^{2}$ The choice of one or another technique usually depends on the criteria of the surgeon and the characteristics of the patient, although in recent years there has been an attempt to opt for minimally invasive surgeries, displacing laparotomic and laparoscopic colposuspension and making suburethral synthetic bands the "gold standard".

The most recent suburethral bands are the single incision sling (SIS) which were developed with the aim of reducing surgical time and minimizing complications associated with traditional suburethral bands (erosions or perforations of the bladder, vagina or urethra, or chronic pain). To achieve this objective, the SIS is shorter and their fixing system does not go through the obturator foramen.

However, there is some controversy when it comes to determining which band offers the best results in terms of efficacy, surgical time, and postoperative complications; medium-long-term studies are scarce or almost nil.

The objective of this study is to compare SIS with transobturator bands (TO), in terms of efficacy (objective continence and degree of satisfaction) and long-term postoperative complications.

\section{Material and methods}

An observational, prospective, single-center study was carried out for 7years (2012-2019) at the Valladolid University Clinical 
Hospital (Spain), in women who had undergone surgery for SUI using suburethral bands, TO or SIS.

All patients were evaluated in the Pelvic Floor Unit by detailed anamnesis, physical examination, exclusion of a urinary tract infection and evaluation of incontinence (cough test with a full bladder, $250-300 \mathrm{ml}$ verified by ultrasound and Bonney test), as well as a gynecological ultrasound to study the presence of urethral hypermobility and rule out pathological postvoid residual (PVR). Urodynamic studies (UDS) were only performed in cases of suspected intrinsic deficiency of the urethral sphincter and complex urinary incontinence.

The inclusion criteria were: pure SUI or mixed urinary incontinence (MUI) with a predominance of stress symptoms, a positive cough test in consultation with urethral hypermobility, and failed or unwanted previous conservative treatment

Exclusion criteria were the presence of neurogenic incontinence and PVR $>100 \mathrm{ml}$. Age and body mass index (BMI) did not limit inclusion in this study.

The following were studied and compared between both groups: anthropometric variables (age and BMI), obstetric history (parity, vaginal delivery with fetus $>4 \mathrm{~kg}$, instrumented delivery with forceps), comorbidity (arterial hypertension, respiratory, neurological or psychiatric pathology), previous anti-incontinence surgery, associated pelvic organ prolapse surgery (POP), type of UI (SUI, MUI), severity of SUI (grade I, II, III, according to the importance of the triggering situation, that is, UI with great effort, moderate effort or minimal effort, respectively), number of pads used, previous urodynamic study, and surgical time.

If the patient had MUI, the urgency component was first treated with behavioral and pharmacological interventions for at least 6 months.

For the placement of the TO band, the patients were operated with hospital admission. The surgeries were performed by two surgeons, under regional or general anesthesia. The length of stay varied depending on whether there was associated prolapse surgery or not. Before discharge, a PVR of less than $100 \mathrm{ml}$ was verified.

The SIS was inserted by the same two surgeons, as an outpatient procedure, under sedation and local anesthesia. They were discharged the same day, after verifying a PVR of less than $100 \mathrm{ml}$. All patients signed the informed consent prior to the surgical procedure.

The types of in-out TO band used were: I-Stop Braun ${ }^{\circledR}$ (B. Braun SA, Barcelona) and TOA ${ }^{\circledR}$ (Presurgy SL adjustable sling, Madrid), and with the out-in needle path Monarc $\AA$ bands were placed until 2015 (AMS, Inc., Minnetonka, USA).

The types of SIS used were: Altis ${ }^{\circledR}$ (Coloplast Corp., Minneapolis, MN, USA) and Ophira ${ }^{\circledR}$ (Promedon, Cordoba, Argentina).

During the first 2 years, the follow-up was carried out in the Pelvic Floor Unit consulta-tion by physical examination, cough test, measurement of residual urine and visual satisfaction scale.

Afterwards, annual follow-up was stablished, by telephone interview, carrying out an exhaustive anamnesis on symptoms related to SUI, urgency and urge urinary incontinence. Patient satisfaction was established by themselves, on a scale between 0 and 10 .

Three main variables were evaluated:

a. Total urinary continence: no urine leakage, neither with effort nor urgency. b. Objective cure rates: assessed by cough test with a full bladder during the first 2 years, and subsequently, carrying out an exhaustive anamnesis on symptoms related to SUI.

c. Subjective cure rate and degree of satisfaction: firstly it was established using the visual satisfaction scale (score 0-10) and after the second year, by telephone interview, with a numerical scale from 0 to 10 .

d. Two secondary variables were collected:

e. Complications: immediate ( $<7$ days), intermediate ( $\geq 7-30$ days) and late ( $\geq 1$ month)

f. Surgical time (in minutes).

\section{Statistical analyses}

The Kolmogorov-Smirnov test was applied for quantitative variables to determine the type of distribution. The Student t-test was used to study quantitative variables with a normal distribution, and the U-Mann-Whitney test was used otherwise. The Chi-square test with Yates correction was used to study categorical variables. In all cases, less than 0.05 was the value taken as statistically significant. SSPS v. 23 was the statistic software used.

\section{Ethical approval}

This study was authorized by the ethics and research committee of the eastern health area of Valladolid (Code: FO-P07-12, approval date: 03-18-2016 and start date of the study: 02-13-2015) (Appendice-1). Verbal informed consent was obtained from all the patients who were part of it. We collected the data from the clinical history of the first two years after surgery, and we completed by telephone follow-up until the sixth year.

\section{Results}

\section{Population characteristics}

A total of 289 patients were included, 109 TO and 180 SIS. The demographic characteristics, concomitant pathology, and obstetric history are shown in Table 1.

The mean age was significantly higher in the SIS group, with no significant differences in BMI. More patients performed some physical activity in the SIS group.

Regarding the obstetric history, both groups had similar percentages of nulliparity, forceps and deliveries of more than $4 \mathrm{~kg}$. Regarding medical pathology, a significantly higher frequency of arterial hypertension was found in TO patients.

The types of bands used are shown in Table 2. In-Out insertion was more frequent for TO bands. Regarding the SIS, almost twice as many Altis ${ }^{\circledR}$ as Ophira ${ }^{\circledR}$ were inserted.

When comparing the symptoms of the patients, significant differences were found both in the type of UI and in the degree of SUI (Table 3), but not in the number of pads used before surgery, nor in previously performed UDS.

Significant differences were found in the association of anterior, middle and posterior compartment POP surgery, in favor of TO band (Table 3).

The indication for surgery due to recurrence of SUI was more frequent in TO band and the surgical time was significantly shorter with SIS (Table 3). 
Table I Comparison of the anthropometric characteristics of the patients, concomitant pathology and obstetric history

\begin{tabular}{|c|c|c|c|}
\hline Características & TO $(n=109)$ & SIS $(n=180)$ & $\mathbf{p}$ \\
\hline \multicolumn{4}{|l|}{ Demográficas } \\
\hline Age $($ mean $\pm S D)$ & $65.6 \pm 9.5$ & $58.4 \pm 11.6$ & $<0,00 I^{b}$ \\
\hline $\mathrm{BMI}($ mean $\pm \mathrm{SD})$ & $29.4 \pm 9.9$ & $26.9 \pm 4.5$ & $\mathrm{Ns}^{\mathrm{a}}$ \\
\hline Daily Physical Activity & $21 / 109$ (19.27\%) & $74 / \mid 80$ (4I. II\%) & $<0,\left.00\right|^{c}$ \\
\hline \multicolumn{4}{|l|}{ Obstetric history } \\
\hline Parity Nulliparity & 4/I07 (3.74\%) & $4 / 180$ (2.22\%) & $N s^{c}$ \\
\hline$\geq$ I Vaginal delivery & $103 / 107$ (96.26\%) & I76/I80 (97.77\%) & \\
\hline Fórceps & $8 / 68$ (II.76\%) & $|2 /| 2 \mid$ (9.92\%) & $\mathrm{Ns}^{\mathrm{c}}$ \\
\hline Delivery $>4 \mathrm{~kg}$ & $22 / 74(29.73 \%)$ & $36 / 133(27.07 \%)$ & $\mathrm{Ns}^{\mathrm{c}}$ \\
\hline \multicolumn{4}{|l|}{ Medical pathology } \\
\hline $\mathrm{AH}$ & $45 / 109$ (4I.28\%) & $53 / 180(29.44 \%)$ & $0,039^{c}$ \\
\hline Respiratory & $7 / 109$ (6.42\%) & $18 / 180(10 \%)$ & $\mathrm{Ns}^{\mathrm{c}}$ \\
\hline Psyquiatric & $24 / 109$ (22.02\%) & $48 / / 80$ (22.22\%) & $N s^{c}$ \\
\hline Neurologic & $4 / 109$ (3.67\%) & $5 / 180$ (2.77\%) & $\mathrm{Ns}^{\mathrm{c}}$ \\
\hline Tobacco $>5$ per day & $8 / 107$ (7.8\%) & $29 / 179$ (16.20\%) & $\mathrm{Ns}^{\mathrm{c}}$ \\
\hline
\end{tabular}

$\mathrm{SD}$, standard deviation; Ns, non-significant statistical difference; $\mathrm{AH}$, arterial hypertension

a, T-Student test; b, U-Mann-Witney test; c, Chi-square test

Table 2 Types of bands used in the study

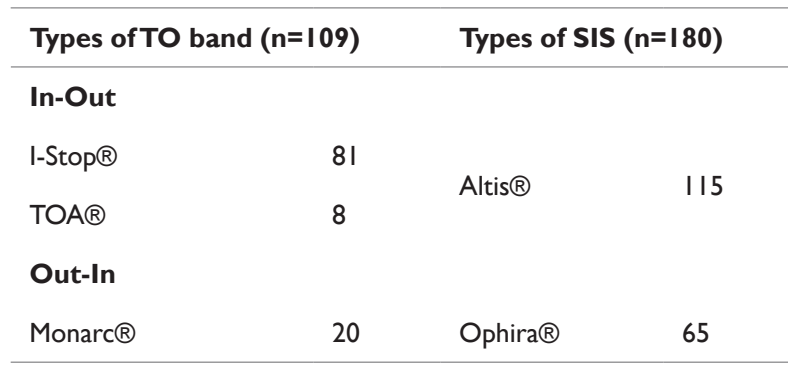

Table 3 Comparison of the type of Ul, degree of SUI, number of pads, previous urodynamic study, associated POP surgery and surgery time

\begin{tabular}{|c|c|c|c|}
\hline & TO $(n=109)$ & SIS $(n=180)$ & $\mathbf{p}$ \\
\hline \multicolumn{4}{|l|}{ Type of incontinence } \\
\hline Pure SUI & $38(34.86 \%)$ & 115 (63.89\%) & $<0,001^{\mathrm{c}}$ \\
\hline MUI & $60(55.05 \%)$ & $65(36.11)$ & \\
\hline Hidden & II (10.09\%) & 0 & \\
\hline \multicolumn{4}{|l|}{ SUI grade } \\
\hline I & I (0.92\%) & $2(1.11 \%)$ & $0,001^{\mathrm{c}}$ \\
\hline ॥ & $84(77.06 \%)$ & 161 (89.44\%) & \\
\hline III & $24(22.02 \%)$ & $17(9.44 \%)$ & \\
\hline No. of pads (mean $\pm S D$ ) & $3.35 \pm 1.9$ & $3.89 \pm 1.9$ & $\mathrm{Ns}^{\mathrm{b}}$ \\
\hline Previous urodynamic study & $13 / 109$ (11.93\%) & $23 / 180(12.78 \%)$ & $\mathrm{Ns}^{\mathrm{c}}$ \\
\hline SUI recurrence & $15 / 109(13.76 \%)$ & $1 / 180(0.56 \%)$ & $<0,\left.00\right|^{c}$ \\
\hline
\end{tabular}




\begin{tabular}{|c|c|c|c|c|}
\hline & & TO $(n=109)$ & SIS $(n=\mid 80)$ & $\mathbf{p}$ \\
\hline \multicolumn{5}{|c|}{ Associated POP surgery } \\
\hline • & Anterior compartment & $62 / 109(56.88 \%)$ & $3 / 180(1.67 \%)$ & $<0,00 I^{c}$ \\
\hline • & Hysterectomy & $33 / 109$ (30.28\%) & $2 / 180(1.11 \%)$ & $<0,\left.00\right|^{c}$ \\
\hline • & Posterior compartment & $35 / 109$ (32.11\%) & $\mathrm{I} / \mathrm{I} 80(0.56 \%)$ & $<0,00 I^{c}$ \\
\hline • & Manchester operation & $2 / 109$ (1.83\%) & $2 / 180(1.11 \%)$ & $N s^{c}$ \\
\hline • & Repair enterocele & $4 / 109$ (3.67\%) & $2 / 180(1.11 \%)$ & $\mathrm{Ns}^{\mathrm{c}}$ \\
\hline \multicolumn{2}{|c|}{ Surgery time (minutes; mean $\pm S D$ ) } & $70.83 \pm 28.78$ & $52.32 \pm 58.08$ & $0.04^{\mathrm{a}}$ \\
\hline
\end{tabular}

UI, urinary incontinence; SUI, stress urinary incontinence; SD, standard deviation; Ns, non-significant statistical difference; POP, pelvic organ prolapse.

a, T-Student test; b, U-Mann-Witney test; c, Chi-square test

\section{Post-surgical complications and surgery time}

There are no significant differences in immediate $(<7$ days $)$, intermediate ( $\geq 7-30$ days) and late ( $\geq 1$ month) complications (Table 4).

Table 4 Post-surgical complication rate

\begin{tabular}{|c|c|c|c|}
\hline & TO $(n=109)$ & $\operatorname{SIS}(n=180)$ & pa \\
\hline Immediate & $13.76 \%(15)$ & $13.33 \%(24)$ & Ns \\
\hline Hematoma & I & 4 & \\
\hline Hematoma Surgery & I & 0 & \\
\hline Fever & I & 0 & \\
\hline Urinary tract infection & 2 & 3 & \\
\hline Urinary retention & 12 & II & \\
\hline Bladder perforation & I & 0 & \\
\hline Intermediate & $6.42 \%(7)$ & $10 \%(18)$ & Ns \\
\hline Fever & I & 0 & \\
\hline Hematoma & I & 2 & \\
\hline Abscess & 0 & 3 & \\
\hline UTI & 3 & 6 & \\
\hline Urinary retention & 2 & 5 & \\
\hline Urinary catheter & I & I & \\
\hline Late & $28.44 \%(3 I)$ & $37.22 \%(67)$ & Ns \\
\hline De novo urgency & $8(25.80 \%)$ & 30 (44.78\%) & 0,023 \\
\hline Urinary retention & 2 & 2 & \\
\hline Extrusion & 2 & 9 & \\
\hline Pain & II (35.48\%) & 12 (I7.91\%) & \\
\hline Urinary catheter & 4 & 7 & \\
\hline SUI recurrence & I5 (48.39\%) & $31(42.27 \%)$ & \\
\hline Uretrolysis & $3(9.68 \%)$ & 0 & 0,025 \\
\hline
\end{tabular}

UTI, urinary tract infection; Ns, non-significant statistical difference

a. Chi-square test
Among the immediate complications, we found 1 bladder perforation with TO and 1 hemorrhage from the inferior epigastric artery into the space of Retzius with TO that required urgent surgical repair.

Regarding late complications, although globally there are no differences, some events are significant individually, such as greater urgency de novo with SIS $(16.67 \%$ vs $7.34 \%, p=0.023)$ and 3 urethrolysis due to voiding dysfunction with TO vs 0 with SIS $(\mathrm{p}=0.025)$. There is a non-significant trend towards a higher frequency of extrusion and recurrence of SUI with SIS, and a higher percentage of late pain with TO $(10.19 \%$ vs $6.67 \%)$.

\section{Objective and subjective cure rate}

The number of patients who completed the follow-up annually is reflected in Table 5.

Table 5 Number of patients who completed the follow-up in each year

\begin{tabular}{lll}
\hline & TO $(\mathrm{n}=109)$ & SIS $(\mathrm{n}=1 \mathbf{1 8 0})$ \\
\hline I year & 95 & 161 \\
2 years & 79 & 142 \\
3 years & 71 & 115 \\
4 years & 52 & 81 \\
5 years & 38 & 45 \\
6 years & 30 & 14 \\
7 years & 14 & 4
\end{tabular}

No significant differences were found between both groups in the 7-year follow-up in relation to objective cure (cough test or telephone survey of SUI symptoms). A tendency to decrease objective healing was observed from the sixth year with TO and from the seventh year with SIS (Figure 1).

Total continence includes not having urinary losses, neither urgency nor effort. No significant differences were found between the two groups and the tendency is to worsen, especially after the sixth year (Figure 2).

The subjective cure of the patients was determined by asking their level of satisfaction on a nominal scale from 0 to 10 . There are no significant differences between the two bands, maintaining a high degree of satisfaction, which decreases slightly after the sixth year, without decreasing below 6 points (Figure 3 ). 


\section{Objective Cure}

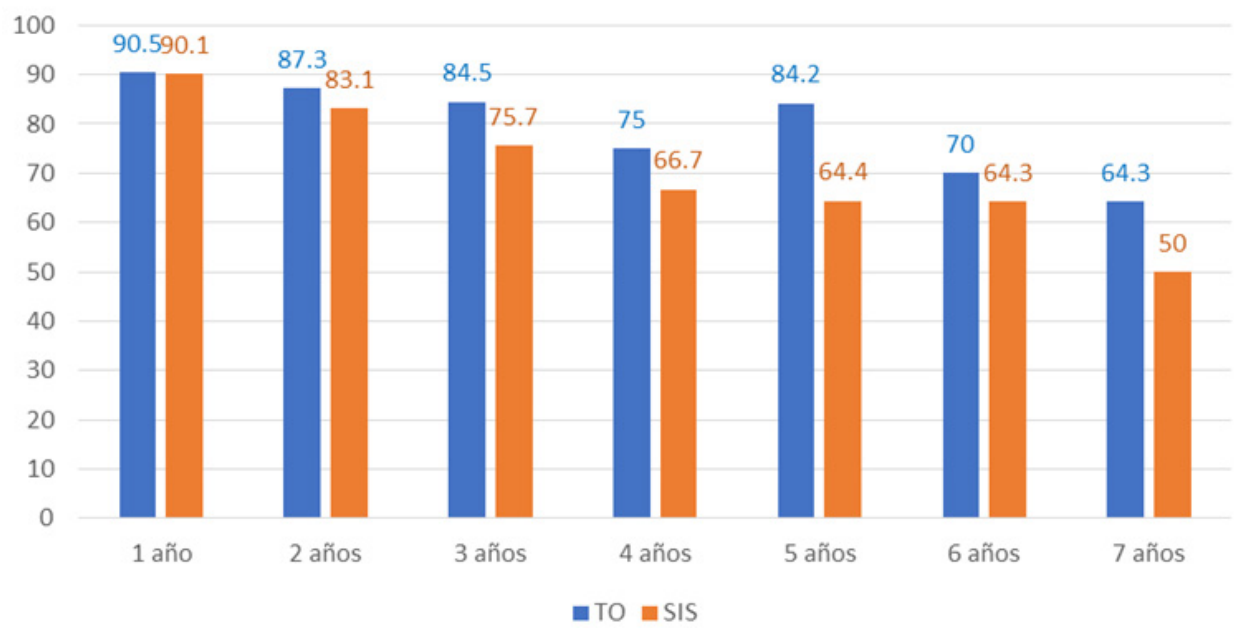

Figure I Objective cure rate (percentage) over 7 years of patients operated on with TO compared with SIS.

\section{Total continence}

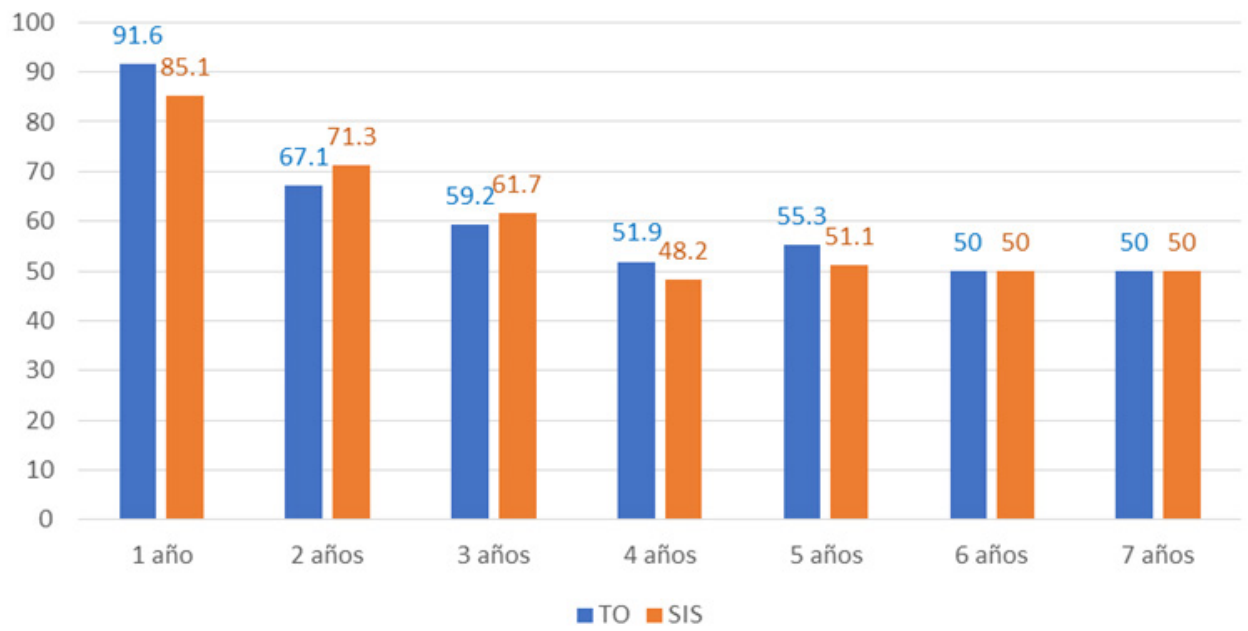

Figure 2 Total continence (percentage) over 7 years of patients operated with TO compared with SIS.

\section{Degree of satisfaction}

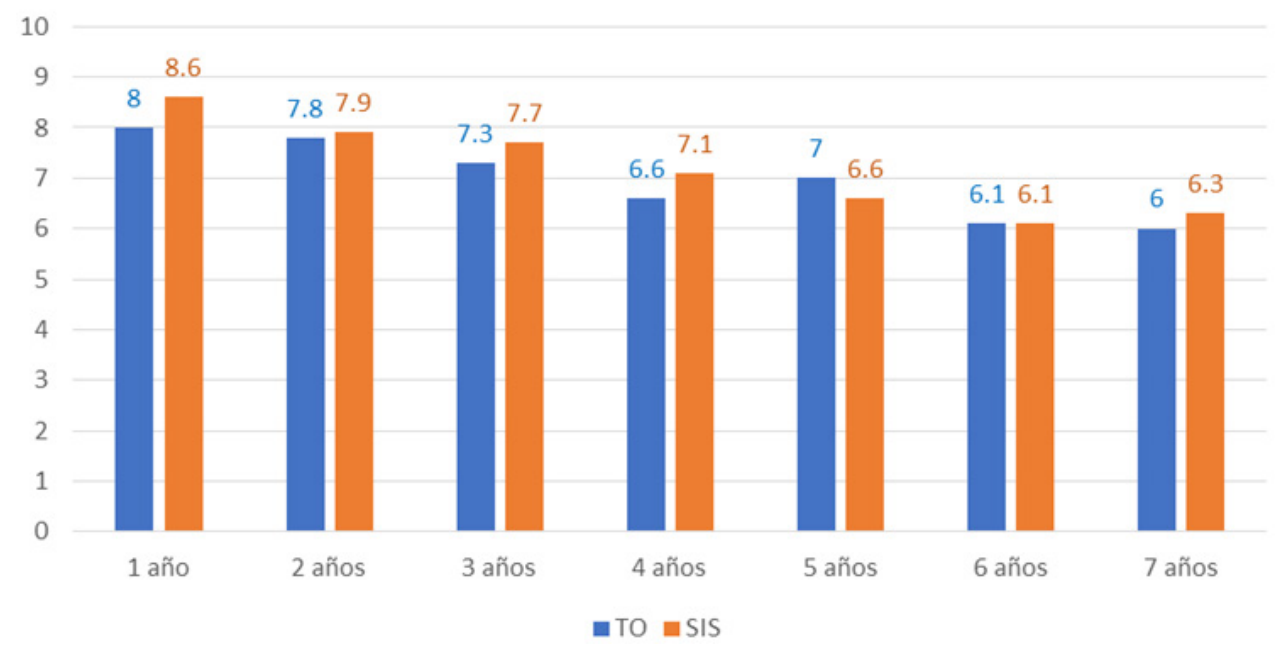

Figure 3 Degree of satisfaction (score on numerical scale) of the patients operated on with TO compared with SIS during the 7-year follow-up. 


\section{Discussion}

In the last decade, at least a dozen articles have been published comparing SIS with TO, of which the vast majority study inserted TO using the inside-out technique. These publications mainly focus on comparing objective cure, subjective cure, and surgical complications. Although most are randomized clinical trials (RCT), the follow-up is usually short term (1-2 years), ${ }^{3-11}$ we only found one at 5 years 12 but none longer term.

In our sample, SIS patients were younger (58.4 years versus 65.6 years, $\mathrm{p}<0.001)$ and practiced physical activity more frequently $(41.11 \%$ vs $19.27 \%, \mathrm{p}<0.001)$ than TO patients. On the other hand, the patients operated with TO presented arterial hypertension more frequently $(41.28 \%$ vs $29.44 \%, \mathrm{p}=0.039)$, possibly because they were older than the SIS group.

Regarding the type of incontinence they presented, SUI was more frequent in patients who were candidates for SIS $(63.89 \%$ vs $34.86 \%, \mathrm{p}<0.001)$, while MUI was more frequent in candidates for TO $(55.05 \%$ vs $36.11 \%, p<0.001)$. In both groups, the most frequent Grade of SUI was II, but there were significant differences regarding Grade III SUI, which was higher in TO $(22.02 \%$ vs $9.44 \%, \mathrm{p}=0.001)$. These differences could also be due to the fact that the TO sample has a higher mean age.

Patients with TO associate in greater proportion, concomitant surgery of POP of the 3 compartments, compared to SIS, which was statistically significant, and when a SUI recurrence, a TO band was inserted more frequently than a SIS $(13.76 \%$ vs $0.56 \%, \mathrm{p}<0.001)$

This is because in our center, when a patient requires surgical repair of POP and simultaneous SUI, a TO band is placed (exceptionally an SIS band).

Our study reveals that the objective cure rate at 1 and 2 years is high for both bands, but without significant differences (TO vs SIS, 1 year: $90.5 \%-90.1 \%$ and 2 years: $87.3 \%-83.1 \%$ ). Similar results are also found by other authors for 1 year ${ }^{7,9-11}$ and 2 year- follow up. ${ }^{6,8}$ Some authors report significant differences in objective continence at one year in favor of TO, such as $\mathrm{Hinoul}^{4}$ (TO $97.6 \%$ vs SIS $83.6 \%$, $\mathrm{p}<0.05$ ), Amat $^{3}$ (TO 90\% vs SIS 87.5\%, p=0.015) and Hota ${ }^{5}$ (TO $90.0 \%$ vs SIS $47.6 \%, \mathrm{p}<0.05)$.

We did not find significant differences in terms of objective cure rate between TO and SIS during the 7-year follow-up, but there is a trend to worsen from the sixth year for TO and the seventh year for SIS (TO vs SIS, 6 years: 70\%-64.3\% and 7 years: $64.3 \%-50 \%$ ).

A 5-year randomized clinical trial ${ }^{12}$ does not report any significant differences in objective continence either, being $82.6 \%$ for TO and $68.4 \%$ for SIS ( $p>0.05$ ), similar figures to ours at 5 years (TO $84.3 \%$ and SIS $64.4 \%, \mathrm{p}>0.05)$.

When examining total continence, the rates are lower than the objective cure rate and we found no significant differences between the two bands over 7 years. It is striking how it drops drastically from 3 years for TO $(59.2 \%)$ and from 4 years for SIS (48.2\%). We postulate as possible causes, the higher frequency of MUI and older age in women with TO band, and the appearance of de novo urgency as a more frequent late complication after SIS band than after TO.

The subjective cure rate was evaluated by the degree of satisfaction (numerical scale from 0 to 10 ) and we did not discover significant differences between bands. The trend describes high satisfaction during the first 2 years (TO vs SIS, 1 year: 8 and 8.6, 2 years: 7.8 and
7.9) and subsequent progressive decrease, with a greater decrease in the sixth year, but the scores for both surgeries did not they descend from 6 to the seventh year.

The literature reviewed also found no significant differences in subjective healing, assessed by different scales (PGI-I, KHQ, ICIQUI, I-QOL, PFDI-20, UDI-6) or in the short term $\left(13-5.7,{ }^{9-11}\right.$ and 2 years $\left.{ }^{6,8}\right)$ or in the medium term $\left(5\right.$ years $\left.{ }^{12}\right)$.

The shorter surgical time spent in the insertion of SIS in our setting is significant, a finding reported by Xin. ${ }^{10}$ However, we must consider that in our study women with TO more frequently associated concomitant repair of POP, which lengthens the time. Theoretically it could be postulated that the insertion of the SIS is faster than the TO, due to the less dissection of the paraurethral space that it requires, but some authors do not find significant differences in these times $\left(\right.$ Grigoriadis $\left.^{8}\right)$.

The frequency of complications in both procedures did not differ globally or by period. But in both cases, it is observed how they tend to be more frequent from the first month $(28.44 \%$ TO and $37.22 \%$ SIS, $\mathrm{p}<0.05)$. Among patients with late complications, we found significant differences in de novo urgency, more frequent with SIS $(44.78 \%$ vs $25.80 \%, \mathrm{p}=0.023)$ and in urethrolysis, more frequent with TO ( $9.68 \%$ vs $0 \%, p=0.025)$. Although not significantly, late pain with TO could be more frequent ( $35.48 \%$ vs $17.91 \%, \mathrm{p}>0.05)$.

The recurrence of SUI, a very feared late complication, was not significantly different between the two bands, although the percentage was slightly higher with TO (48.39\% vs $42.27 \%$, p $>0.05)$.

In general, the authors reviewed also did not observe significant differences in relation to complications. ${ }^{6,7,10,11}$ Less postoperative pain statistically significant is observed with SIS $^{3,4,7,10}$ and a trend towards a higher frequency of de novo urgency ${ }^{7}$ and extrusion ${ }^{6}$ with SIS. These findings are consistent with our results.

\section{Conclusion}

i. In the 7-year follow-up of women operated with TO and SIS, we did not find significant differences in terms of objective cure, degree of satisfaction and complications.

ii. A non-significant decreasing trend is found in objective healing from the sixth year in the case of TO and from the seventh year in the case of SIS, as well as a progressive decrease in the degree of satisfaction, which becomes more evident from the sixth year for both bands.

iii. As significant late complications, we observed more urgency de novo with SIS and urethrolysis with TO.

iv. Both bands can be placed as an effective and safe treatment for SUI. It would be appropriate to design longer-term studies and analyze the possible reasons why the SIS produces a higher frequency of de novo urgency.

\section{Each authors' contribution to the manuscript}

Carmen E. Badillo-Bercebal, PhD: Manuscript writing, Data Collection

Sonia De-Miguel-Manso, PhD: Project development, Manuscript writing, Data Collection.

Elena García-García, PhD: Data Collection, Manuscript writing.

Dakota Viruega-Cuaresma, PhD: Data Collection. 
Julio A. Gobernado-Tejedor, $\mathrm{PhD}$, MD: Project development, Stadistical analisis.

María López País, PhD, MD: Data Collection.

\section{Acknowledgments}

None.

\section{Funding}

No funding was obtained for the implementation of this study.

\section{Conflicts of interest}

The authors declare that they have no conflict of interest.

\section{References}

1. Ford AA, Rogerson L, Cody JD, et al. Mid-urethral sling operations for stress urinary incontinence in women. Cochrane Database Syst Rev. 2017;7(7):CD006375

2. Burkhard FC, Bosch JL, Cruz F, et al. European Association of Urology. EAU guidelines on urinary incontinence in adults. 2016.

3. Amat L, Franco E, Vicens JM. Contasure-Needleless compared with transobturator-TVT for the treatment of stress urinary incontinence. Int Urogynecol J. 2011;22(7):827-833.

4. Hinoul P, Vervest HA, den Boon J, et al. A randomized, controlled trial comparing an innovative single incision sling with an established transobturator sling to treat female stress urinary incontinence. $J$ Urol. 2011;185(4):1356-1362.

5. Hota LS, Hanaway K, Hacker MR, et al. TVT-Secur (Hammock) versus TVT-Obturator: a randomized trial of suburethral sling operative procedures. Female Pelvic Med Reconstr Surg. 2012;18(1):41-45.
6. Bianchi AH, Jarmy-Di-Bella ZI, Castro RA, et al. Randomized controlled trial comparing TVT-O and TVT-S for the treatment of stress urinary incontinence: 2-year results. Int Urogynecol J. 2014;25(10):1343-1348.

7. Mostafa A, Agur W, Abdel-All M, et al. Multicenter prospective randomized study of single-incision mini-sling vs tension-free vaginal tape-obturator in management of female stress urinary incontinence: a minimum of 1-year follow-up. Urology. 2013;82(3):552-559.

8. Grigoriadis C, Bakas P, Derpapas A, et al. Tension-free vaginal tape obturator versus Ajust adjustable single incision sling procedure in women with urodynamic stress urinary incontinence. Eur J Obstet Gynecol Reprod Biol. 2013;170(2):563-566.

9. Masata J, Svabik K, Zvara K, et al. Comparison of the efficacy of tension-free vaginal tape obturator (TVT-O) and single-incision tensionfree vaginal tape (Ajust ${ }^{\mathrm{TM}}$ ) in the treatment of female stress urinary incontinence: a 1-year follow-up randomized trial. Int Urogynecol J. 2016;27(10):1497-1505.

10. Xin X, Song Y, Xia Z. A comparison between adjustable single-incision sling and tension-free vaginal tape-obturator in treating stress urinary incontinence. Arch Gynecol Obstet. 2016;293(2):457-463.

11. Maturana AP, Palos CC, Ghersel FR, et al. Randomized controlled trial comparing mini-sling with transobturator sling for the treatment of stress urinary incontinence. Int Urogynecol J. 2019;31(9):1925-1931.

12. Tommaselli GA, D'Afiero A, Di Carlo C, et al. Tension-free vaginal tapeobturator and tension-free vaginal tape-Secur for the treatment of stress urinary incontinence: a 5-year follow-up randomized study. Eur J Obstet Gynecol Reprod Biol. 2015;185:151-155. 